
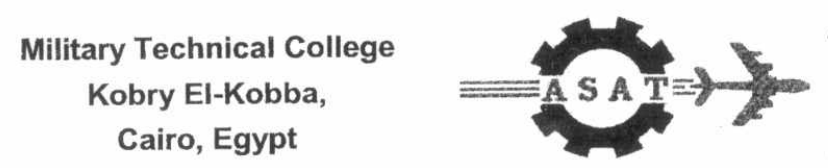

11-th International Conference on Aerospace Sciences \&

Aviation Technology

\title{
LIFE PREDICTION MODELING UNDER FATIGUE LOADING FOR ALUMINUM METAL MATRIX COMPOSITES
}

\author{
Abdellatif S. H. *, Shoukry M. K ${ }^{\star \star}$, and Rabeeh B. M. ${ }^{\star \star \star}$
}

\begin{abstract}
Metal matrix composites are currently being considered for use in many applications for their high strength-to-weight and stiffness-to-weight ratios, high wear resistance, and high thermal resistance.

The present work focuses on the study of crack propagation in Aluminum monolithic and aluminum metal matrix composites reinforced with continuous stainless steel fibers at $4 \%, 8 \%$, and $13 \%$ volume fractions with five plies, and unidirectional structural configuration.

Based on experimental evidence, a micromechanical modeling approach was developed for the prediction of fatigue life and the model was compared with actual fatigue lives for these materials.
\end{abstract}

\section{Key words}

Fatigue, crack growth, life prediction, metal matrix composites.

* Assistant Lecturer, Dept. of Mech. Engineering, Chair of Mech. design and production MTC, Cairo.

** Associate Professor, Dept. of Mech. Engineering, Chair of Mech. Mech. design and production MTC, Cairo.

*** Associate Professor, Dept. of Mech. Engineering, Chair of Auto. MTC, Cairo 


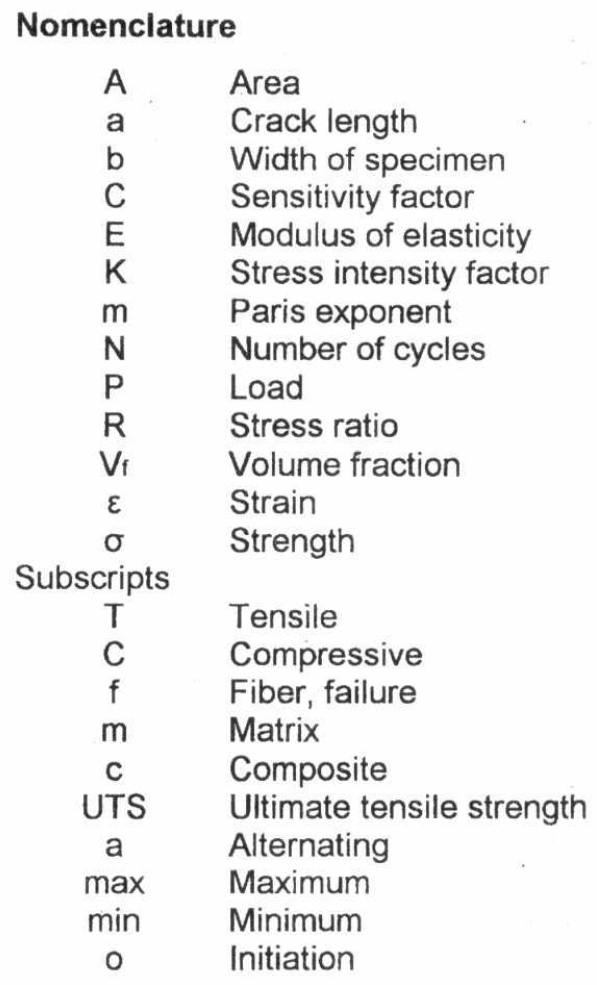

\section{INTRODUCTION}

Early detection of damage is critical for the prevention of catastrophic failure, especially for metallic structures subjected to cyclic loading.

Metal Matrix Composites are a class of materials with potential for a wide variety of structural and thermal management application. MMCs are of interest because they offer the opportunity to tailor a material with a combination of properties unavailable in any single material, e.g., combining a very high tensile strength and modulus of elasticity of various types of fibers with the low density of metals such as aluminum, titanium, or magnesium to obtain a composite material with higher strength-to-density ratio than any single known alloy [1].

Paris and co-workers $[2,3]$. applied the fracture mechanics concept of crack tip stress intensity to fatigue and the correlation between crack-growth rate and stress intensity amplitude has become most popular.

The objective of the present work is to study the crack growth behavior of these materials under cyclic loading. In addition, the Paris constants are used to predict the lives of these materials. Then the experimentally measured values are compared with theoretically derived ones and relevant calculations are drawn 


\section{Material}

The tested materials are produced according to the fiber volume fraction based on a matrix of aluminum reinforced with unidirectional fibers of common austenitic stainless steel.

\section{Aluminum Matrix}

The matrix is made of commercially pure aluminum sheets having a thickness of 0.5 $\mathrm{mm}$ characterized by their low density. The chemical composition and mechanical properties of these aluminum foils are listed in Tables 1.a and 1.b [4].

\section{Stainless Steel Fibers}

Austenitic stainless steel fibers are used as the reinforcement for the matrix. They are characterized by their high strength, high ductility, and high corrosion resistance. The fibers used here are designated according to the AISI and ASTM by the code $304(18 / 8)$. Chemical composition and physical \& mechanical properties of these fibers are listed in Tables2.a and 2.b [5].

\section{Hot Pressing}

The hot pressing technique is used for fabrication of aluminum monolithic matrix and stainless steel reinforced aluminum MMCs. Samples are produced by the "sheetfiber- sheet" technique, Fig. 1.

An optimum thin continuous and uniform inter-diffusion zone is obtained in the Al. MMCs reinforced with stainless steel fibers prepared at hot pressing parameters, namely temperature $T=640^{\circ} \mathrm{C}$, curing time $t=15 \mathrm{~min}$., and pressure $P=65 \mathrm{MPa}$. This optimum interface gives the best mechanical properties [6]; therefore the previous parameters are adopted in the present work in production of test samples.

\section{Test specimen}

The test specimens are selected and prepared according to the standard specifications ASTM D3039-76, [7]. The specimen geometry and dimensions are shown in Fig. 2.

\section{EXPERIMENTAL WORK}

Fatigue crack growth tests are conducted for Al. monolithic matrix and Al. MMCs with different volume fractions $(4 \%, 8 \%$, and $13 \%)$. They are conducted at a constant stress range $\Delta \sigma$ corresponding to $0.5 \sigma_{\text {UTS }}$ and stress ratio R equals zero using a sinusoidal wave form at a frequency of $10 \mathrm{~Hz}$. at room temperature. The tests are carried out on a servo-hydraulic MTS (material test system) machine model 803.

Single-edge notched specimens are used $\left(a_{0} / w=0.3, w=30 \mathrm{~mm}\right)$ where $a_{0}$ is the initial length of notch and $w$ is the width of specimen, Fig.3. The initial notches are cut perpendicular to the fiber direction using wire cutting machine.

To measure the crack growth periodically with number of cycles during test, a scale with minimum deviation of $0.1 \mathrm{~mm}$ is fixed on the specimen, parallel to the crack growth plane while a hand microscope is used to magnify the crack. The specimen 
side is coated by a thin film of lacquer, which is cracked by the same value during crack growth to increase the visibility of the crack.

\section{RESULTS}

\section{Fatigue crack growth test results}

Fatigue crack growth (FCG) behavior of Al. matrix and composites with different values of $V_{f}$ is necessary to study and to predict the life of these materials. Fig.4. presents the history of crack growth under a pulsating loading for Al. monolithic matrix and $\mathrm{Al}$. MMCs. In this figure $\mathrm{N}$ represents the number of cycles and a represents the corresponding crack length in meters.

For Al. monolithic matrix that the crack grows exponentially, slowly at the beginning, then the rate of propagation increases rapidly. The final, complete, failure takes place at point (c). The figure also shows that the fatigue histories of composite specimens reach the critical point earlier, with a crack of a smaller size, and that the fatigue crack growth properties of the composites are better than those of the matrix due to failure and crack arresting mechanisms. By increasing the fiber volume fraction value from $4 \%$ to $13 \%$, the FCG behavior gets better. Considering a fatigue load that fluctuates at constant amplitude where the stresses vary between $\sigma_{\max }$ and zero, the range of the stress intensity factor can be expressed as

$$
\Delta K=K_{\max }-K_{\min }=\alpha \sigma_{\max } \sqrt{\pi a}
$$

Where a (for a single edge notch, SEN, specimen) in tension may be expressed as [3]

$$
\alpha=f_{1}=1.12-0.231\left(\frac{a}{b}\right)+10.55\left(\frac{a}{b}\right)^{2}-21.72\left(\frac{a}{b}\right)^{3}+30.39\left(\frac{a}{b}\right)^{4}
$$

Figs. 5.a through 5.d present the crack growth rates per cycle $(\mathrm{da} / \mathrm{dN})$ plotted versus $\Delta \mathrm{K}$ for test specimens.

The presented test data can be modeled using the relation

$$
\frac{\mathrm{da}}{\mathrm{dN}}=\mathrm{C}\left(\Delta \mathrm{K}_{\text {tip }}\right)^{\mathrm{n}}
$$

Which is known as the fatigue crack propagation law (Paris law $[2,3]$ ) where $C$ is a constant factor and $\mathrm{m}$ is an exponent taken from test results. These two constants are obtained numerically by curve fitting. Table 3 lists the values of Paris constants $C$ and $\mathrm{m}$. It can be noted that by increasing the fiber volume fraction, the value of $\mathrm{C}$ decreases while the value of $m$ increases.

To reveal the effect of fiber volume fraction on fatigue crack growth propagation, the curves in Figs. $5 a$ to $5 \mathrm{~d}$ are merged in Fig. 6 where logarithmic crack growth rates per cycle $[\log (\mathrm{da} / \mathrm{dN})]$ are plotted versus logarithmic stress intensity factor $[\log (\Delta K)]$

The curves in Fig. 6 shows that the $(\mathrm{da} / \mathrm{dN})$ curves for the composites are much steeper compared to those of the matrix, i.e., (mcomposite $>$ mmatrix) which means that the composites exhibit slower crack growth rates than the matrix, and that increasing 
the fiber volume fraction value causes the crack growth rates to decrease. At lower $\Delta \mathrm{K}$ values, fiber matrix interfaces can act as crack blunters retarding the crack growth. However, as $\Delta \mathrm{K}$ increases, the fiber can no longer withstand the stress cycling and starts fracturing providing crack initiation sites.

\section{Micromechanical modeling and life prediction}

This section demonstrates how fatigue lives can be predicted using mechanistically based micromechanical models. The predictions obtained from the models are compared with experimental data obtained from matrix material and composites. Micromechanical modeling is observed based on understanding damage mechanisms in both matrix and composites separately.

The technique used in the present work is to integrate the Paris law

$$
\frac{\mathrm{da}}{\mathrm{dN}}=\mathrm{C}\left(\Delta \mathrm{K}_{\mathrm{tip}}\right)^{\mathrm{m}}
$$

Rearranging:

$$
\mathrm{da}=\mathrm{C}\left(\Delta \mathrm{K}_{\mathrm{tip}}\right)^{\mathrm{m}} \mathrm{dN}
$$

The values of $\mathrm{C}$ and $\mathrm{m}$ are listed in Table 3 for each individual tested material. Introducing integration limits yields

$$
\int_{N_{0}}^{N_{f}} d N=\int_{a_{0}}^{a_{f}} \frac{1}{C\left(\Delta K_{\text {tip }}\right)^{m}} d a
$$

In Equation (6) $\Delta \mathrm{K}_{\text {tip }}$ is the effective stress intensity factor measured in (MPa $\sqrt{\mathrm{m}}$ ) and the subscript tip refers to its value at the tip of crack. $N_{f}$ is the total fatigue life which is the sum of cycles prior to crack initiation and number of cycles for crack propagation. $N_{0}$ is the number of cycles required for crack initiation and is found by experiment to have one half the value of $N_{f}$ approximately. $a_{0}$ is the initial crack length, measured during incremental fatigue tests[10]. $a_{f}$ is the crack length at the instant of sample failure and is found by experiment to be one half of the sample thickness[10].

For zero stress ratio, $R=K_{\min } / K_{\max }=0$, the value of $\Delta K_{\text {tip }}$ is related to the stress intensity factor by $[8,9]$

$$
\Delta \mathrm{K}_{\text {tip }}(\mathrm{a})=2 \mathrm{~K}_{\text {tip }}(\mathrm{a})
$$

where the stress intensity factor, $\mathrm{K}_{\text {tip }}(\mathrm{a})$, differs according to the type of crack and is estimated using empirical formulae as functions of actual crack length. For edge and double edge cracks it is given by $[8,9]$

$$
\mathrm{K}_{\text {tip }}(\mathrm{a})=\sigma \sqrt{\pi \mathrm{a}} \frac{1.122-0.561\left(\frac{\mathrm{a}}{\mathrm{C}_{\max }}\right)-0.015\left(\frac{\mathrm{a}}{\mathrm{C}_{\max }}\right)^{2}+0.091\left(\frac{\mathrm{a}}{\mathrm{C}_{\max }}\right)^{3}}{\sqrt{1-\left(\frac{\mathrm{a}}{\mathrm{C}_{\max }}\right)}}
$$


And for center crack it is given by [8]

$$
\mathrm{K}_{\text {tip }}(\mathrm{a})=\sigma \sqrt{\pi \mathrm{a}} \frac{1.0-0.5\left(\frac{\mathrm{a}}{\mathrm{C}_{\max }}\right)+0.326\left(\frac{\mathrm{a}}{\mathrm{C}_{\max }}\right)^{2}}{\sqrt{1-\left(\frac{\mathrm{a}}{\mathrm{C}_{\max }}\right)}}
$$

In the last two equations $(7,8), \sigma$ refers to the applied stress range and $C_{\max }$ is the maximum crack length (half of the specimen width).

Integrating equation (6) between the appropriate limits and substituting for the corresponding constants yields the fatigue life prediction (S-N relation) for each concrete case.

\section{Fatigue life prediction for Al. monolithic matrix}

Consistent with experimental observations, matrix cracking is assumed to initiate from the outer surface of the sample (edge crack) with initiated crack length of $\sim 130 \mu \mathrm{m}$ while the crack length at sample failure has the length of $\sim 1350 \mu \mathrm{m}$. Referring to values for $\mathrm{C}$ and $\mathrm{m}$ from Table 3 , the $\mathrm{S}-\mathrm{N}$ relation is drawn and compared with the experimental result [10], Fig.7. for the monolithic specimens.

\section{Fatigue life prediction for Al. MMCs}

Consistent with experimental observations, cracking is assumed to initiate in two different stages. In the first stage, cracking initiates as a center crack in the outer plies (center crack) with initiated crack length equals the diameter of the fiber, $\sim 250 \mu \mathrm{m}$, while in the second stage, the crack propagates in the double edge crack form (double edge crack). The crack length at sample failure has the length of 1500 $\mu \mathrm{m}$. Referring to corresponding values for $\mathrm{C}$ and $\mathrm{m}$ from Table 3, the S-N relations for Al. MMCs with different $V_{f}$ values are drawn and compared with the corresponding experimental relations for each case[10], Figs. 8 through 10.

The Figs. 7 through 10 does not show high agreement between the experimental results and the predicted fatigue lives obtained from the fracture mechanics model due to inaccurate measuring instruments.

\section{CONCLUSIONS}

1. Matrix cracking generally initiates at approximately one half of the total fatigue life (0.5Nf).

2. Failure takes place as soon as the crack length reaches a value of one half the specimen thickness.

3. Fatigue crack growth properties of the composites are better than those of the matrix material due to failure and crack arresting mechanisms.

4. By increasing the fiber volume fraction value, the crack behavior gets better. In other words, the capability of the matrix to resist (blunt) the crack growth propagation is higher. One can conclude that the reinforcements increase the material's crack resistance.

5. Fatigue lives predicted using mathematical models based on FCG test results show good agreement with experimental one. 


\section{REFERENCES}

[1] Bhagwan B. A., J. B. Lawrence, "Analysis and Performance of Fiber Composites", John Wiley \& Sons Inc., 1990.

[2] Plumbridge W. J., "Fatigue Crack Propagation in Metallic and Polymeric Materials", Journal of Materials Science 7, pp. 939-962, 1972.

[3] Eliahu Zahavi, Fladimir, "Fatigue design, Life Expectancy of Machine Parts", A Solomon Press Book (CRC) Inc., 1996.

[4] ASM International Hand Book, "Properties and Selection; Nonferrous Alloys and Special Purpose Materials", "Metals Handbook", ASM International Hand Book

[5] J.R.Davis, "ASM Specially Hand Book: Stainless Steels", ASM International Materials, 1996

[6] M.E.Shamekh, M. M. Sallam, B. Rabeeh, "Mechanical Properties and Fracture Mechanisms for Al. MMCs", M. Sc. Thesis, M.T.C., 2001

[7] ASTM, "Standards and Literature References for Composite Materials", ASTM, 1990.

[8] B. Rabeeh V. O. Soboyejo, S.I. Rokhlin, "Aerospace Material Damage Characterization and Life predictions", Seventh ASAT Conference, 1997

[9] B.Rabeeh V.O. Soboyejo, S.I. Rokhlin, A. B. O. Soboyejo, "Mechanisticallybased Models for the Predictions of Fatigue Damage in a Beta Titanium Alloy", Fatigue and Fracture of Engineering Materials \& Structures 21, pp. 557-568, 1998.

[10] S.H.abdellatif, M. K.Shoukry, B.M Rabeeh, "Fatigue Damage and Life Prediction for Al. MMCs", M. Sc. Thesis, M.T.C., 2001 
Table (1a) Chemical composition of the used commercially pure aluminum foils [2]

\begin{tabular}{|c|c|c|c|c|c|c|c|}
\hline Al purity & $\mathrm{Si}$ & $\mathrm{Fe}$ & $\mathrm{Cu}$ & $\mathrm{Zn}$ & $\mathrm{Mn}$ & $\mathrm{Mg}$ & $\mathrm{Ti}$ \\
\hline Min & Max. & Max. & Max. & Max. & Max. & Max. & Max. \\
$99.5 \%$ & $0.25 \%$ & $0.4 \%$ & $0.05 \%$ & $0.05 \%$ & $0.05 \%$ & $0.05 \%$ & $0.03 \%$ \\
\hline
\end{tabular}

Table (1b) Mechanical properties of the used commercially pure aluminum foils [2]

\begin{tabular}{|c|c|c|c|}
\hline $\begin{array}{c}\text { Yield Strength } \\
(\mathrm{MPa})\end{array}$ & $\begin{array}{c}\text { Tensile Strength } \\
(\mathrm{MPa})\end{array}$ & $\begin{array}{c}\text { Shear Modulus } \\
(\mathrm{GPa})\end{array}$ & $\begin{array}{c}\text { Plastic Elongation } \\
(\%)\end{array}$ \\
\hline 34 & 90 & 65 & 33 \\
\hline
\end{tabular}

Table (2a) Chemical composition of used austenitic stainless steel Type 304[3]

\begin{tabular}{|c|c|c|c|c|c|c|c|c|}
\hline AISI & $\% \mathrm{C}$ & $\% \mathrm{Cr}$ & $\% \mathrm{Ni}$ & $\% \mathrm{~S}$ & $\% \mathrm{Si}$ & $\% \mathrm{P}$ & $\% \mathrm{Mn}$ & $\% \mathrm{Fe}$ \\
\hline 304 & 0.056 & 20.64 & 7.028 & 0.03 & 0.34 & 0.031 & 1.545 & $\mathrm{R}$ \\
\hline
\end{tabular}

Table (2b) Mechanical and physical properties of used fiber [3]

\begin{tabular}{|c|c|c|}
\hline $\begin{array}{c}\text { Elastic Modulus } \\
(\mathrm{GPa})\end{array}$ & $\begin{array}{c}\text { Tensile Strength } \\
(\mathrm{MPa})\end{array}$ & $\begin{array}{c}\text { Density } \\
\left(\mathrm{g} / \mathrm{cm}^{3}\right)\end{array}$ \\
\hline 198 & 1345 & 8.0 \\
\hline
\end{tabular}

Table. (3) Values of Paris constants

\begin{tabular}{|c|c|c|c|}
\hline Material & $\mathrm{V}_{\mathrm{f}}$ & $\mathrm{C}$ & $\mathrm{m}$ \\
\hline Al. matrix & - & $4 \times 10^{-10}$ & 2.9612 \\
\hline \multirow{3}{*}{ Al. MMCs } & $4 \%$ & $1 \times 10^{-11}$ & 3.252 \\
\cline { 2 - 4 } & $8 \%$ & $9 \times 10^{-13}$ & 3.4123 \\
\cline { 2 - 4 } & $13 \%$ & $3 \times 10^{-13}$ & 3.6328 \\
\hline
\end{tabular}




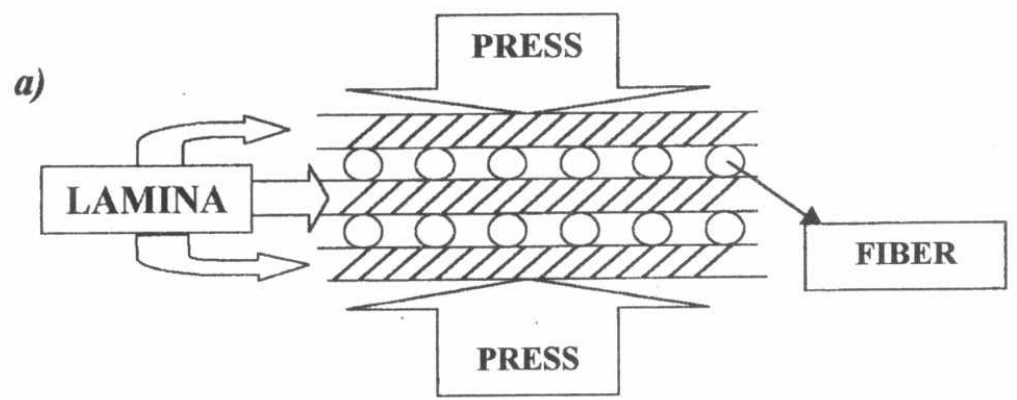

b)

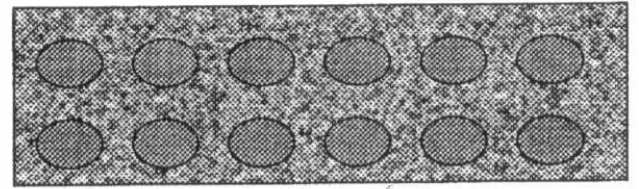

Fig.1 Schematic drawing of the hot pressing technique

$\begin{array}{lll}\text { a) before pressing } & \text { b) after pressing }\end{array}$
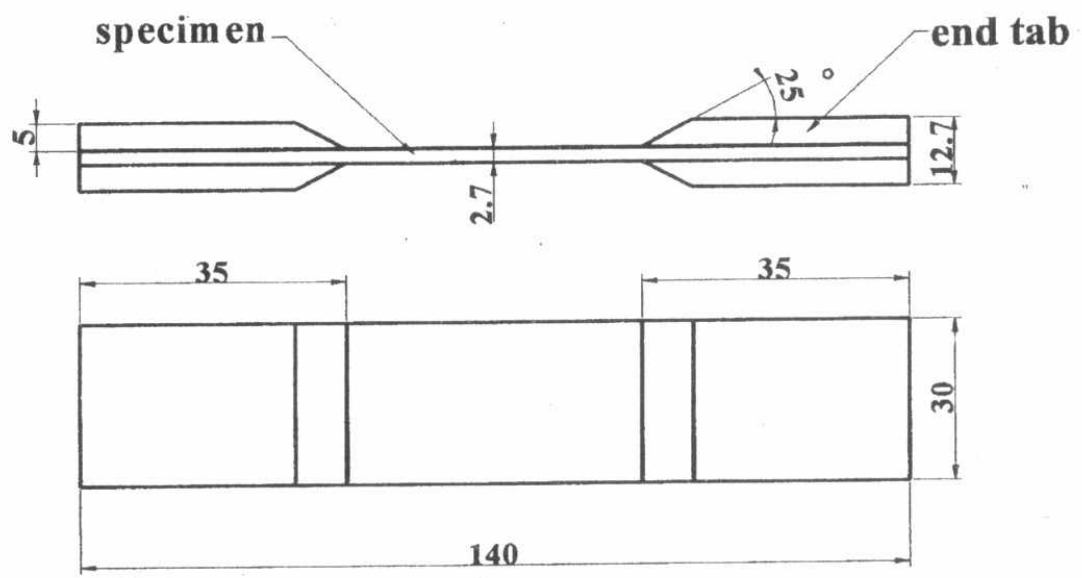

Fig.2 Standard tensile test specimen

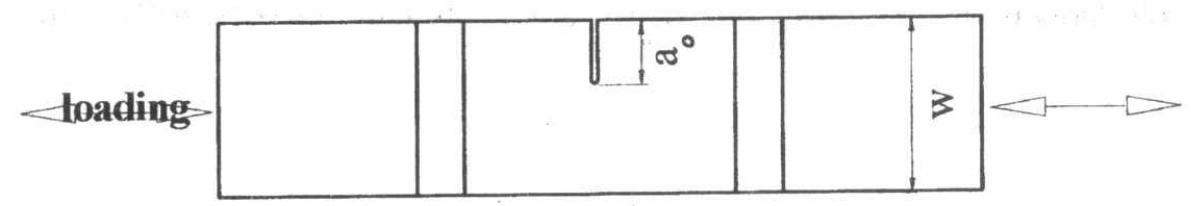

Fig. 3 Single edge notched specimen 


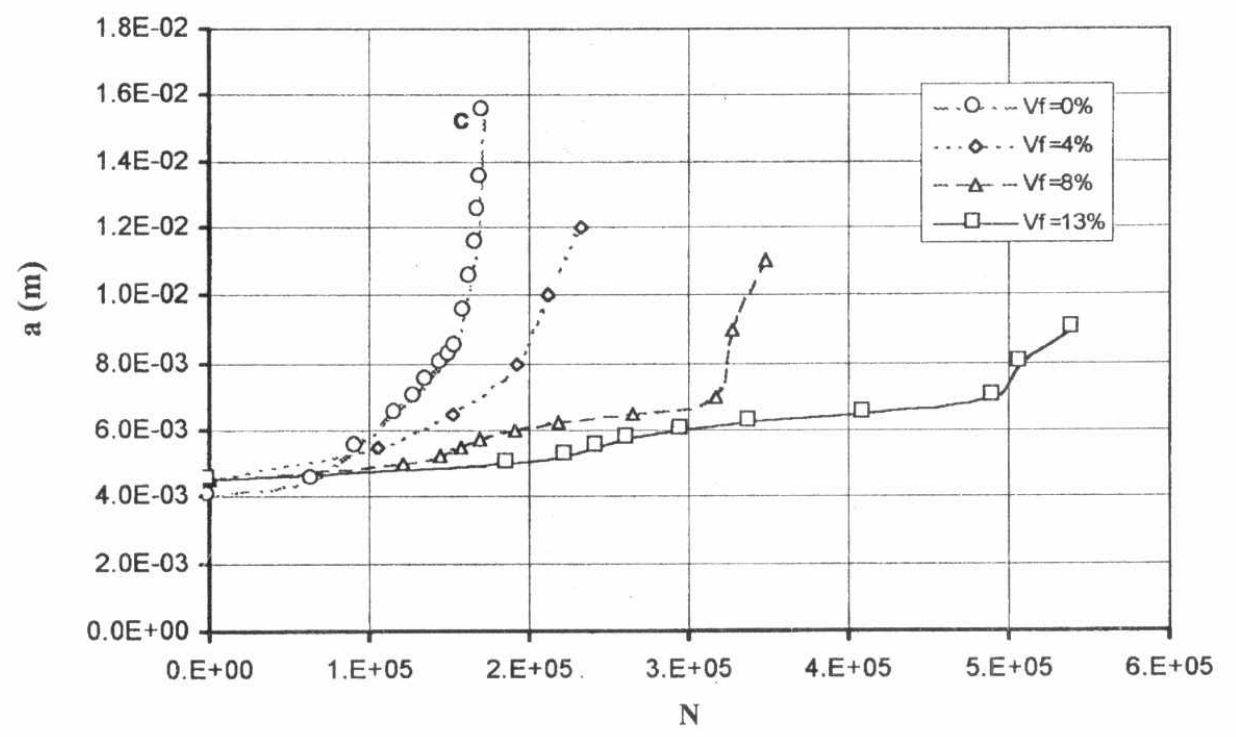

Fig.4 History of crack growth under a pulsating loading

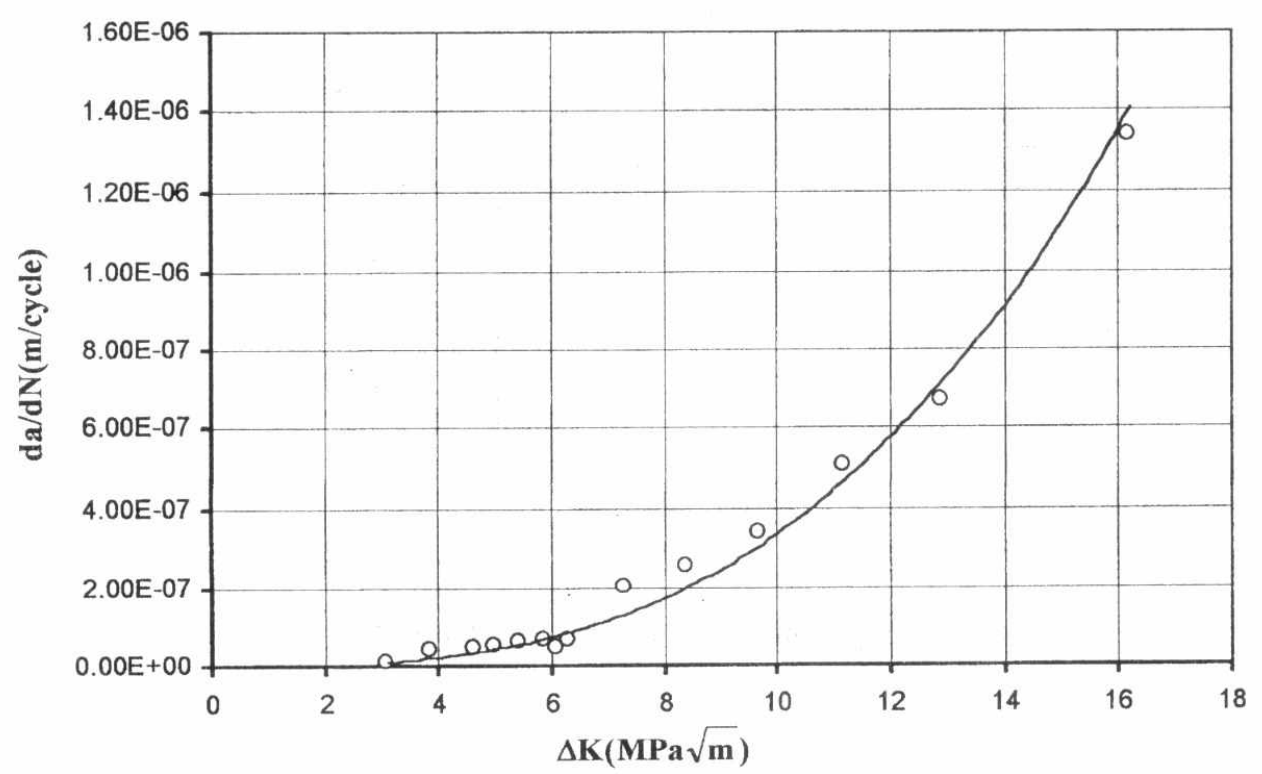

Fig.5a Fatigue crack growth rate vs. stress intensity factor for Al. matrix 


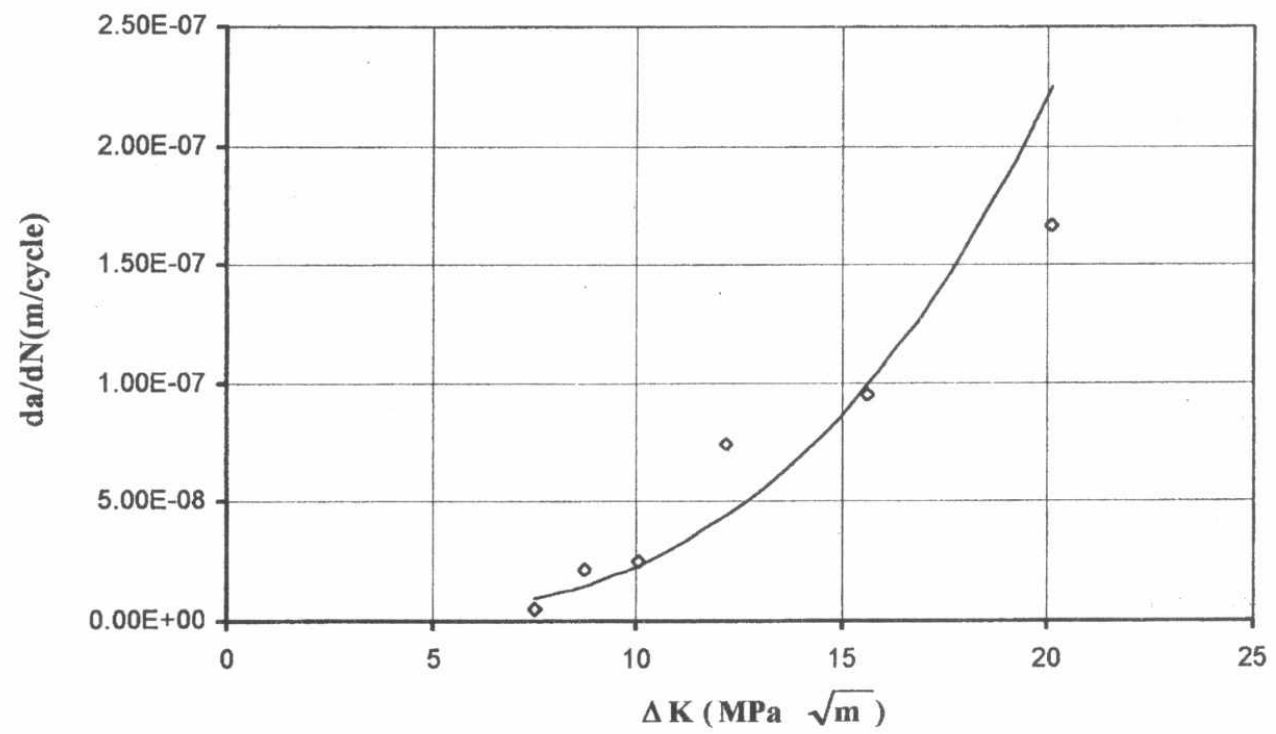

Fig.5b Fatigue crack growtn rate vs. stress intensity factor for Al. MMCs with $V_{f}=4 \%$

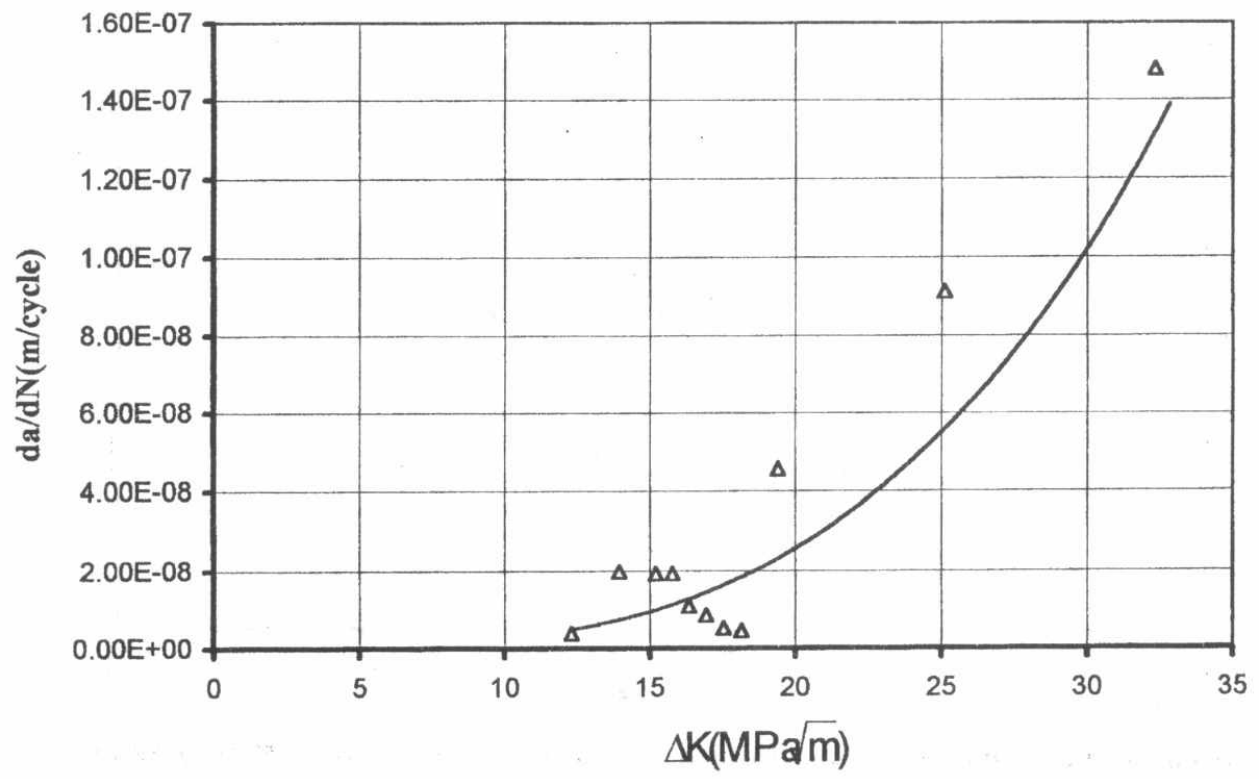

Fig.5c Fatigue crack growth rate vs. stress intensity factor for Al. MMCs with $V_{f}=8 \%$ 


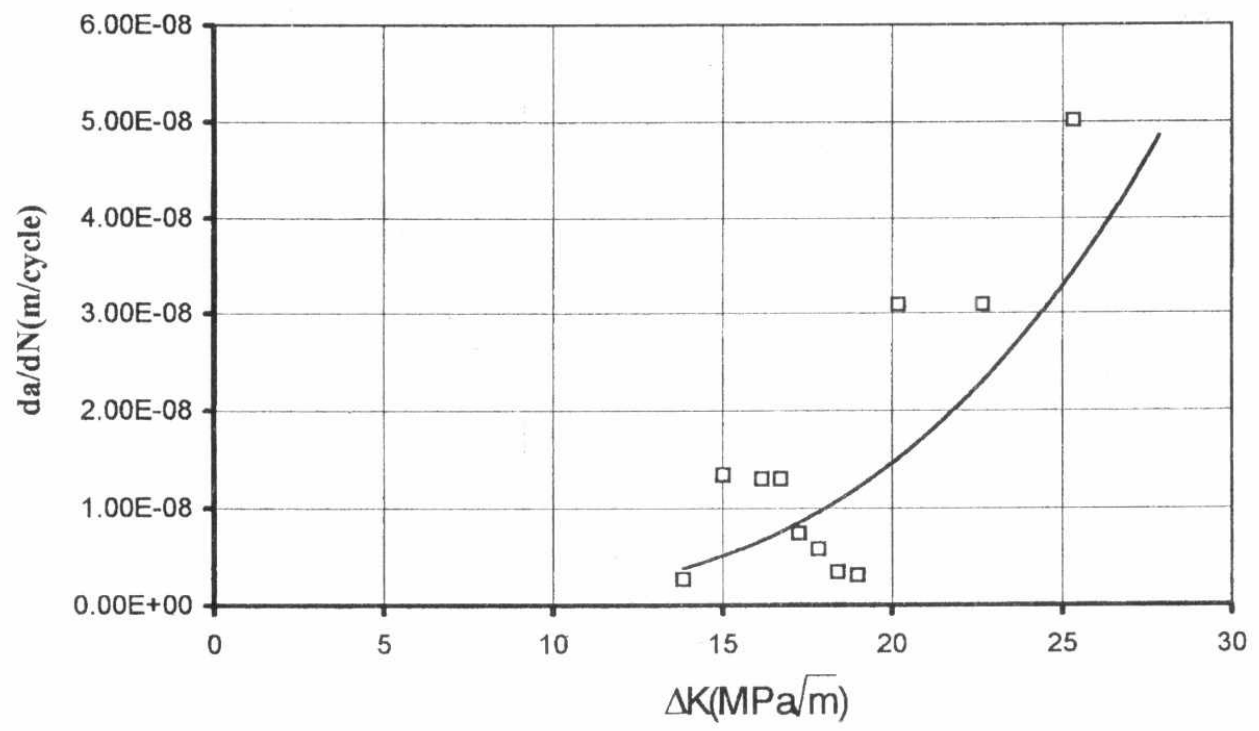

Fig.5d Fatigue crack growth rate vs. stress intensity factor for Al. MMCs with $V_{f}=13 \%$

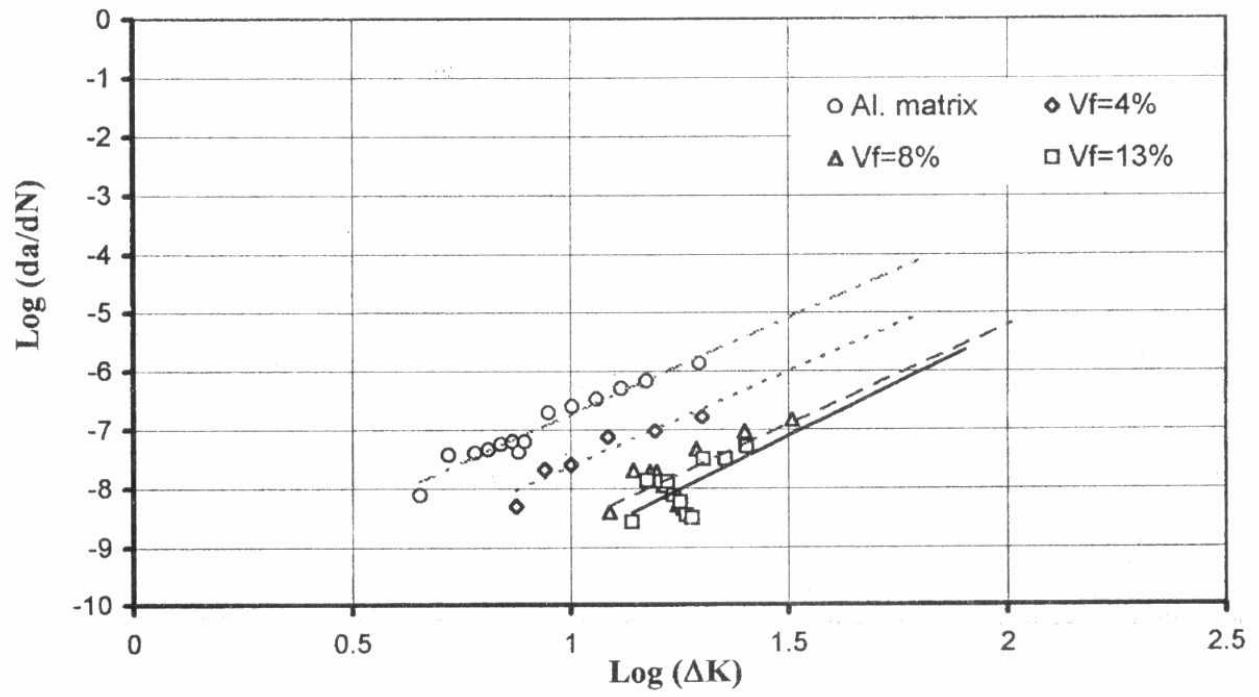

Fig.6 Logarithmic crack growth rate vs. logarithmic stress intensity factor 


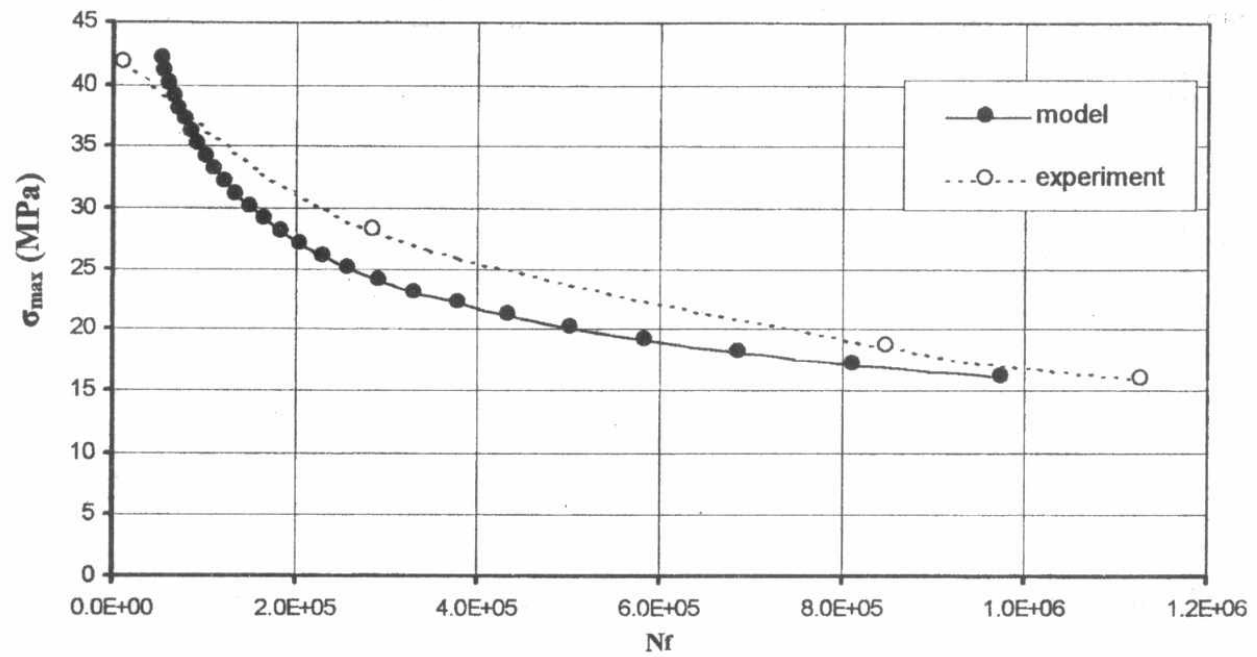

Fig.7 Comparison between predicted and experimentally measured omax-Nf curves for Al. monolithic matrix

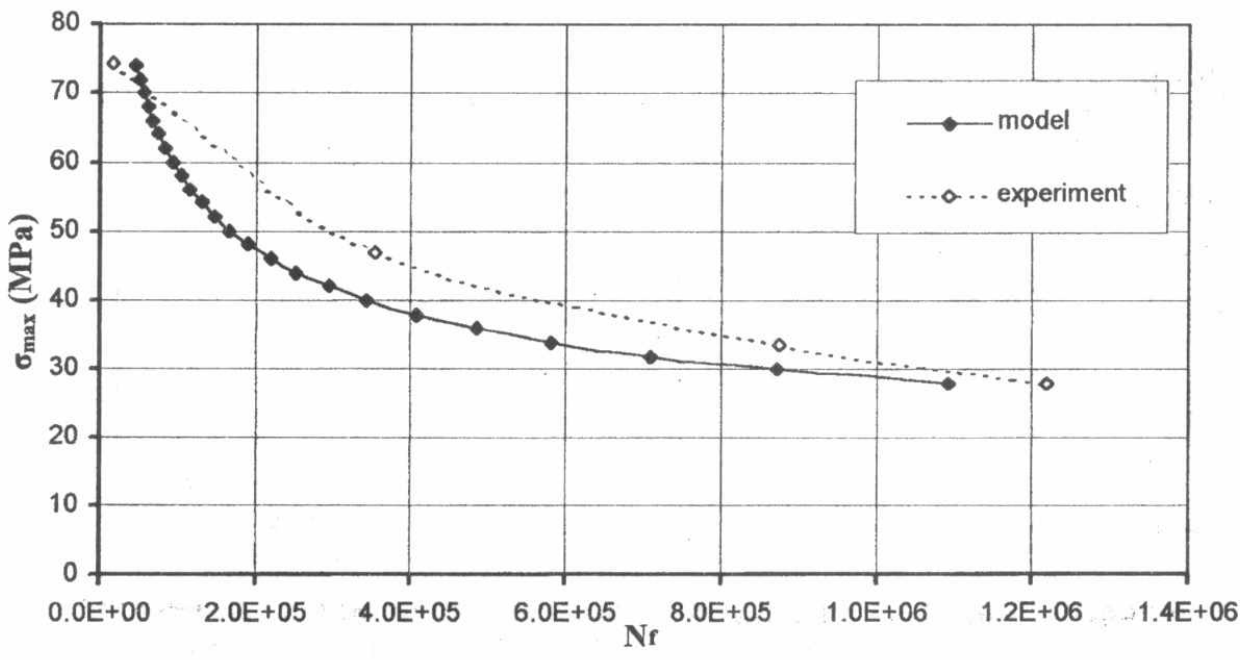

Fig.8 Comparison between predicted and experimentally measured $\sigma_{\max }-\mathrm{Nf}$ curves for Al. MMCs with $\mathrm{V}_{\mathrm{f}}=\mathbf{4} \%$ 


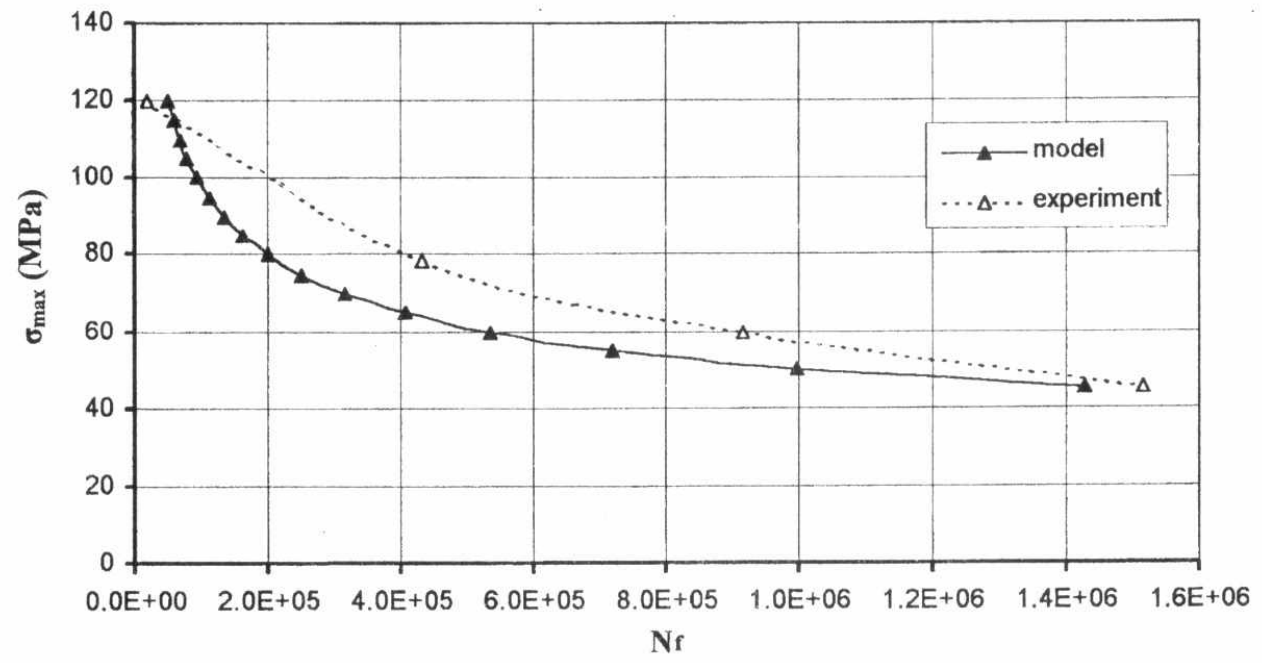

Fig. 9 Comparison between predicted and experimentally measured $\sigma_{\max } \mathrm{Nf}$ curves for Al. MMCs with $\mathrm{V}_{\mathrm{f}}=8 \%$

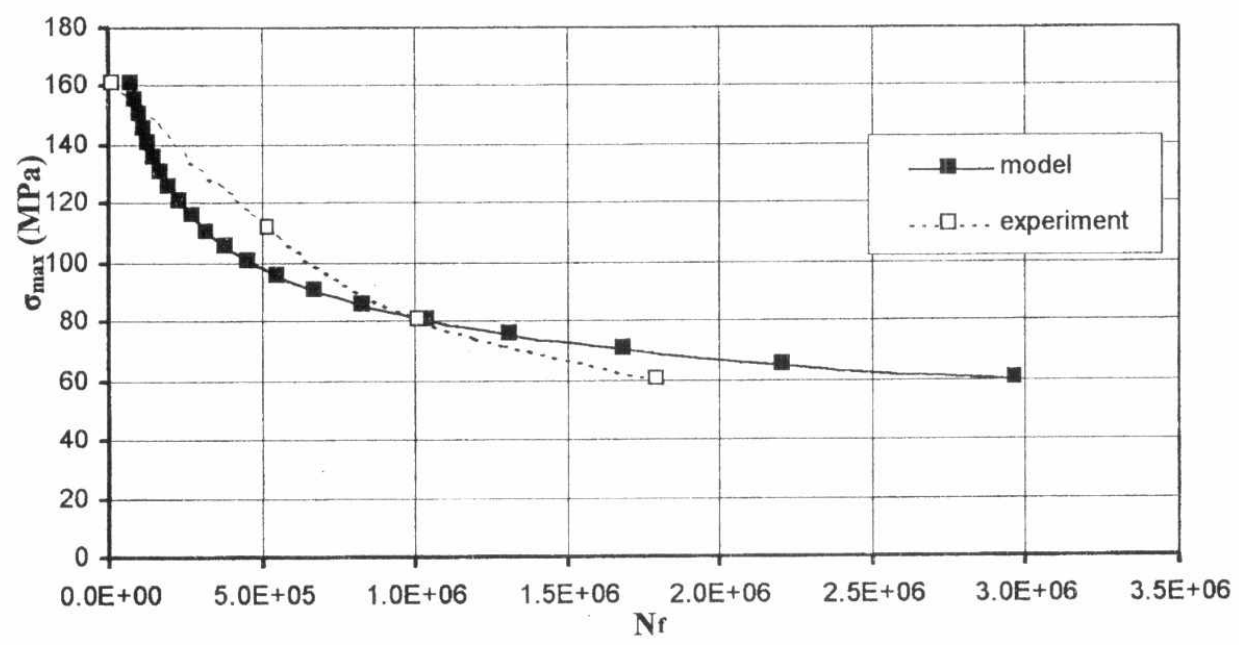

Fig.10 Comparison between predicted and experimentally measured Omax-Nf curves for Al. MMCs with $\mathrm{V}_{\mathrm{f}}=13 \%$ 


\section{ROCKET PROPULSION}




\section{CONTENTS}

PR-01 MODELLING OF MONOPROPELLANT SPACE PROPULSION 411 SYSTEM

A.A.Hashem

PR-02 DESIGN AND TESTING OF THE IGNITION SYSTEM FOR HYBRID ROCKET MOTOR

FAROUK M. OWIS

PR-03 DESIGN OPTIMIZATION AND GEOMETRIC ANALYSIS OF THE SLOTTED SOLID PROPELLANT GRAINS

Zayed, A-N.

PR-04 ATOMIZER EFFECT ON COMBUSTION CHAMBER FLOW CHARACTERISTICS

Ola Rashed, Badiea Hafez, Antal Penninger

PR-05 THE GAS PRESSURE INFLUENCE ON COMBUSTION CHAMBER FLOW CHARACTERISTICS

Ola Rashed 